The book also has chapters on metamorphic reactions (including a discussion of facies), isotope geology, the use of the electron-probe, and a final chapter on metamorphic rocks and the evolution of the Earth. The theoretical sections are on the whole somewhat condensed and the reader will probably only acquire a superficial familiarity with the topics discussed. For example, in the section on isotopes there is no mention of the fundamental equation of radioactive decay and its derivatives as used in isochron diagrams. Similarly, in discussing metamorphic reactions thermodynamics is more or less avoided. These are both cases where more detail would have enabled problems and exercises to be inserted, probably with a considerable benefit to the understanding gained by the reader.

In summary, the book is rather

\section{Three branches of petrology}

Petrology for Students. By S. R. Nockolds, R. W. O'B. Knox and G. A. Chinner. Pp. 435. (Cambridge University Press: Cambridge, 1978.) Hardback $£ 17.50$; paperback $£ 6.50$.

Although Harker's Petrology for Students is discontinued after more than 80 years, this book with the same title and from the same stable is obviously its natural successor. It now has three authors, one for each of the main divisions of petrology. With its emphasis on the description of rock thin sections under the microscope it is very much in the Harkerian mould. This impression is reinforced by the use of many of Harker's original 'microdrawings'. From the amount of detailed information presented, the book seems to be most suitable for the second year of a conventional three-year geology course, but as the three branches of petrology are usually taught separately at this level, its success depends on a consistent approach and level of achievement.

The section on igneous rocks (approximately half the book) provides a thorough and systematic account of the petrography of the main igneous rock groups. with useful supporting information on the major element chemistry. The introductory chapter on textures would be more effective if it was illustrated in situ (rather than referring to the appropriate figures in later chapters), and the chapter on classification is disappointingly brief and makes no concession to other schemes or to recent attempts to disappointing on the topic of metamorphism itself: it is not particularly stimulating, at least partly because it gives very little coverage to some of the fundamental problems of metamorphism such as where the heat comes from and how the study of metamorphism is applied to the understanding of tectonic processes. On the other hand the accounts of metamorphic rocks are rather well done, and the book is worth it for these parts alone. One sympathises with the desire to keep the text short (and cheap) and it may perhaps be impossible to cover all aspects of the subject satisfactorily in a work of this length. None-the-less this book should provide useful background reading for most courses in metamorphic petrology.

K. G. Cox

K. G. Cox is Lecturer in Petrology at the University of Oxford, UK.

standardise nomenclature. A more serious drawback is the persistent emphasis on specific examples, many of which come from obscure localities and represent material the average student is unlikely to meet in the flesh. This whole section has a distinctly oldfashioned flavour; the collection of tacts is carefully curated, but the presentation is lifeless.

The treatment of sedimentary and metamorphic rocks is generally more effective in that it manages to combine the systematic petrography with some discussion of the rock-forming processes. The sedimentary section contains a useful introductory chapter on textures, followed by a logical and upto-date treatment of the main groups of terrigenous and chemical sediments. The metamorphic section is less conventional in that a chapter on textures is followed by discussions of metasomatism and melting, facies classification, regional metamorphism, granulites and eclogites, blueschists, and low-grade metamorphism.

This book is quite good value in terms of the quantity of information provided, but it is not altogether successful as a coherent treatment of the three branches of petrology. It would seem more sensible to invest in separate books on igneous, sedimentary and metamorphic rocks, as these generally provide a more complete picture, combining the descriptive material with a discussion of processes and geological context. Without these petrography can be extremely arid.

\section{W. J. Wadsworth}

W. J. Wadsworth is Senior Lecturer in Geology at the University of Manchester $U K$.

\section{SUSSP 1960-1978}

The Scottish Universities Summer Schools in Physics announce the publication of the proceedings of the 1978 school held at St. Andrews in August:

\section{THE METAL TO NON-METAL TRANSITION IN DISORDERED SYSTEMS}

Editors: D. P. Tunstall, L. R. Friedman Contributors:

N. F. Mott (Cambridge), D. J. Thouless (Birmingham), M. Pollak (California Riverside), N. H. March (Oxford), H. Fritzsche (Chicago), N. E. Cusack (East Anglia), L. R. Friedman (St. Andrews), D. F. Holcomb (Corneli). M. Pepper (Cambridge), J. P. Doumerc (Bordeaux), H. Kanimura (Tokyo), T. M Rice (Bell Telephone), K. Berggren

(Linkoping), J. E. Enderby (Bristol).

$510+x X$ pages. Hard covers £15 (or $\$ 30$ USA) ISBN O 905945026

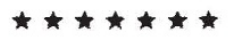

Irevious Publications still available:

\section{7 NUCLEAR STRUCTURE PHYSICS}

Editors: S. J. Hall, J. M. Irvine xiv +708 pages, Hard covers $\$ 15$ (or \$30 USA)

A review of recent advances in theoretical and experimental Nuclear Physics with particular attention to developments in heavy ion physics and electromagnetic interactions with nuclei.

1976

FUNDAMENTALS OF QUARK MODELS

Editors: I. M. Barbour, A. T. Davies xiv +600 pages, Hard covers $\$ 12$ (or \$24 USA)

A systematic presentation of quark models with special attention to the problems of confinement.

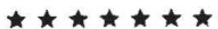

The above volumes may be obtained from:

SUSSP Publications, Physics Department, University of Edinburgh, EDINBURGH EH9 3JZ, Great Britain.

Private subscribers are courteously invited to enclose payment with their order. There is no charge for postage. 